\title{
Stress, duration, and intonation in Arabic word-level prosody
}

\section{Kenneth de Jong and Bushra Adnan Zawaydeh}

Department of Linguistics, 319 Memorial Hall, Indiana University, Bloomington, Ind. 47405, U.S.A.

Received 19th May 1998, revised 12 November 1998, and accepted 18th December 1998

\begin{abstract}
This paper presents the results of a study of the expression of word-level prosody in Jordanian Arabic. The study focuses on the durational, spectral, and fundamental frequency correlates of stress and word-final juncture in the speech of four speakers. Speakers exhibit extensive final lengthening effects and a smaller effect of stress and penultimate lengthening. Stress lengthening correlates with higher first formants, while penultimate lengthening does not. Analyses of fundamental frequency patterns support an analysis in terms of pitch accents associated with stressed syllables and juncture-marking phrasal pitch specifications. Finally, lengthening effects are sensitive to higher level prosodic juncture. These results are discussed in comparison with similar results in studies of English speakers.

(C) 1999 Academic Press
\end{abstract}

\section{Introduction}

This paper presents the results of an investigation into the production of Arabic wordlevel prosody. Thus, this study has two goals. The first is to examine the phonetic correlates of Arabic stress, an apparent prominence marker at the level of the word. The second is to examine similar effects of word-final juncture. This study of Arabic speakers tests the extent to which descriptions of stress and word-final juncture based largely on studies of English can be generalized to other typologically similar languages. In addition, the current study investigates the extent to which word-level prosodic effects are sensitive to higher levels of prosodic structure.

\subsection{Phonological treatments of Arabic stress}

There is a fair amount of phonological literature concerning the placement of stress in various Arabic dialects ${ }^{1}$. The phonological literature typically describes Arabic stress as predictably falling on a particular location in the word, depending on the internal

${ }^{1}$ Some works on the phonology of Arabic stress are the following: Abdo, 1969; Al-Mozaini, 1981; AlMozaini, Bley-Uroman, and McCarthy, 1985; Angoujard, 1990; Brame, 1974; Broselow, 1976; Farwaneh, 1995; Glover, 1998; Haliel, 1984; Hamid, 1984; Hayes, 1995; Irshied, 1984; Kager, to appear; Kaye, 1997; Kenstowicz, 1986, 1983, 1997; Kenstowicz and Abdul-Karim, 1980; Majdi, 1988; McCarthy, 1979, 1980; Odden, 1989; van de Vijver, 1996. 
structure of the syllables making up the word. The pattern of stress location varies considerably in colloquial and modern renditions of Classical Arabic. For example, a Classical Arabic word, such as / katabahu/ 'he wrote it' is said to be produced with antepenultimate stress in Lebanon and Jordan, but with penultimate stress in Egypt (Kaye, 1997). This variation from dialect to dialect makes for an interesting set of case-studies for predicting stress placement. The general pattern of stress placement in Arabic is that the last heavy syllable is typically stressed. Here heavy is a term grouping syllables which are closed and open syllables which contain a long vowel. If there are no heavy syllables in a word, then stress falls in some other predictable location.

Analyses of the various dialects differ in several ways. In some, stress never occurs on the final syllable. Alternatively, final syllables can sometimes bear stress, but only if they contain a long vowel, or in some dialects if they contain a long vowel in a closed syllable. There are differences in the location of stress in words which do not contain heavy syllables. Also, some analyses indicate the presence of secondary stress, while others do not. As is generally the case with comparing prosodic analyses by different authors, it is often difficult to determine which aspects of the analysis are due entirely to differences between the dialects, and which are due to differences in the analytic techniques used by the different authors.

The particular dialect that we investigated is Ammani-Jordanian Arabic, which has a stress pattern identical to Palestinian Arabic (van de Vijver, 1996). In this dialect, stress is said to usually fall on either the penultimate or the antepenultimate syllable. It will fall on the penultimate if the penultimate syllable is heavy, as is shown in (1); otherwise it will fall on the antepenultimate syllable, as is shown in (2). The one complication to this pattern is that final syllables will bear stress if they contain a long vowel or have a final consonant cluster, as is shown in (3). (Bold indicates stress.)

(1) Penultimate stress

$\begin{array}{ll}\text { Jaarak } & \text { 'he participated' } \\ \text { Purdon } & \text { 'Jordan' } \\ \text { maktabha } & \text { 'her desk/office' } \\ \text { binsaameh } & \text { 'we forgive' } \\ \text { saamaћatna } & \text { 'she pardoned us' }\end{array}$

(2) Antepenultimate stress

mafallamak 'he didn't teach you'

fabarada 'he got cold'

Sallamatak 'she taught you'

(3) Final stress

$\begin{array}{ll}\text { darast } & \text { 'I studied' } \\ \text { fakatabt } & \text { 'so I wrote' } \\ \text { Callamt } & \text { 'I taught' } \\ \text { raaseen } & \text { 'two heads' } \\ \text { hammaameen } & \text { 'two bathrooms' } \\ \text { kilmiteen } & \text { 'two words' }\end{array}$




\subsection{The phonetics of stress}

Turning to a phonetic examination of stress location in Arabic, the first matter which must be determined is what are the expected correlates of 'stress'. There are several ways of approaching this question. One approach would take the stand that stress is a purely cognitive phenomenon, and hence cannot be reliably measured in the speech signal. Hayes (1995), for example, lays out a fundamental claim of metrical theory that stress is simply linguistic rhythm, a cognitive entity which could be expressed in various physical fashions. Even accepting this definition of stress, it does not follow that stress is unmeasurable. Even something as abstract as linguistic rhythm can be elucidated with procedures such as metronome entrainment and a phrase repetition task (Cummins, 1997; Tajima, 1998).

The question posed in the current study, however, is much more straightforward. Since there exists a very detailed description of stress based largely on studies of English, to what extent can this description be extended to other languages such as Arabic? Earlier phonetic works on Arabic have given a preliminary indication that Arabic is a very likely language to exhibit the same correlates to stress as does English. Miller (1984) included examples of Arabic in a study which asked hearers with various linguistic training and background to classify the languages according to a rhythmic typology. Arabic was strongly classified with English as a 'stress-timed' language.

Following Fry's pioneering production and perception work on English stress (Fry, 1955, 1958, 1965), we expect three direct, and one indirect correlate of stress. The direct correlates include an increased duration, increased intensity, and more extreme formant values. De Jong (1995) noted that this mixture of properties seems to be indicative of speakers shifting to more output oriented speech (or hyperarticulated, as described in Lindblom, 1990). The indirect correlate is associated with fundamental frequency pattern. Studies on word stress often find an overriding, but complicated association of stress with some aspect of the fundamental frequency pattern. This, following Bolinger (1958) and many others, we take to be indicative of the possible linkage of high and low pitch accents with stressed syllables. Earlier phonetic studies have found similar effects in Arabic. Al-Ani (1992) examined intensity, fundamental frequency, and duration of vowels in words placed in different locations in a phrase. He found that all three typically were greater for syllables which were said to be stressed.

However, it is unclear from these earlier studies of Arabic how the durational measures attributed to stress may be influenced by other prosodic factors such as the position of the stressed syllable in the word. Also it is not clear whether increases in fundamental frequency should be taken as a direct correlate of stress, or as an indicator of pitch accent association with stressed syllables. If Arabic is like English in this regard, the fundamental frequency $\left(\mathrm{F}_{0}\right)$ found on stressed syllables will vary depending on the speakers' choice of intonational markers of discourse function. The difference between typical English declaratives and morphologically covert questions illustrates this effect; stressed syllables in statements typically exhibit high $\mathrm{F}_{0}$ peaks (attributable to high pitch accents), while stressed syllables in morphologically covert questions exhibit $\mathrm{F}_{0}$ valleys (attributable to low pitch accents). (See Pierrehumbert, 1980; Beckman and Pierrehumbert, 1986; and Pierrehumbert and Hirschberg, 1990, for one of several research threads that bears out these claims.) Furthermore, previous analyses of Arabic did not test whether vowel centralization also occurred as a correlate of stress. Finally, previous studies have not investigated any possible connection between word-level effects and higher-level 
prosodic structure. The current study was designed to address these issues with a corpus containing Arabic syllables placed in various prosodic locations in the word and in a higher level phrasal unit. In addition, to examine $F_{0}$ effects in more detail words were produced in question and statement contexts.

\section{Methods}

The target language is Ammani-Jordanian Arabic. Four female native speakers participated in the experiment. Each of the subjects were college educated and multi-lingual in Arabic, English and French. All subjects were tape recorded in Amman during the summer of 1997. Except for the second author, who acted as a subject, all of the subjects were also permanent residents of Amman. We would not expect extensive inter-language effects in the subjects' speech for the following reasons: the data-gathering was performed by a native speaker of Arabic who was familiar to the subjects as a native Ammani, the speakers and the experimenter each had a long history of conversing in Arabic and not in any other language, the recordings were gathered in Amman, and neither French nor English were used at or around the time of the recording.

The corpus consisted of ten types of words spoken in the five prosodic conditions listed in Table I. These conditions placed the target words in final and non-final positions, and in the context of a statement and a question. During recording, each word was spoken in a block consisting of 5 repetitions of the word in each of the five conditions in the order listed in Table I. The word blocks were randomized.

The syllabic structure of the words used in the corpus are shown in Table II. Each word consisted of four light syllables, with stress on the antepenult and with a target light syllable in each of the four positions in the word (types 1-4). In addition, to examine the effect of stress controlled for position, a fifth type (type 5) had the target in the second syllable, but with stress on the penultimate syllable, which was heavy. An additional set

TABLE I. Prosodic conditions of target words

\begin{tabular}{|c|c|c|}
\hline Non-FINAL & FINAL & \\
\hline $\begin{array}{l}\text { 4. STATEMENT- } \\
\text { Non-PHRASE-FINAL }\end{array}$ & $\begin{array}{l}\text { 1. ISOLATION } \\
\text { 2. STATEMENT- } \\
\text { PHRASE-FINAL }\end{array}$ & STATEMENT \\
\hline $\begin{array}{l}\text { 5. QUESTION- } \\
\text { Non-PHRASE-FINAL }\end{array}$ & $\begin{array}{l}\text { 3. QUESTION- } \\
\text { PHRASE-FINAL }\end{array}$ & QUESTION \\
\hline Prosodic condition & Example & Gloss \\
\hline 1. Isolation & fabarada. & 'he got cold' \\
\hline $\begin{array}{l}\text { 2. Statement/Target is Phrase- } \\
\text { Final }\end{array}$ & $\begin{array}{l}\text { 3aaSa } \\
\text { fabarada. }\end{array}$ & $\begin{array}{l}\text { 'he got hungry so he got } \\
\text { cold' }\end{array}$ \\
\hline $\begin{array}{l}\text { 3. Question/Target is Phrase- } \\
\text { Final }\end{array}$ & $\begin{array}{l}\text { 3aaia } \\
\text { fabarada? }\end{array}$ & $\begin{array}{l}\text { 'he got hungry so he got } \\
\text { cold?' }\end{array}$ \\
\hline $\begin{array}{l}\text { 4. Statement/Target is not } \\
\text { Phrase-Final }\end{array}$ & fabarada huna. & 'he got cold here' \\
\hline $\begin{array}{l}\text { 5. Question/Target is not } \\
\text { Phrase-Final }\end{array}$ & fabarada huna? & 'he got cold here?' \\
\hline
\end{tabular}


TABLE II. Word templates

(LIGHT Targets in bold)

\begin{tabular}{|c|c|}
\hline Antepenultimate stress & Penultimate stress \\
\hline $\begin{array}{l}\text { 1. CV } \cdot C V^{\prime} \cdot C V \cdot C V \\
\text { 2. CV } \cdot C V^{\prime} \cdot C V \cdot C V \\
\text { 3. CV } \cdot C^{\prime} \cdot C V \cdot C V \\
\text { 4. CV } \cdot C V^{\prime} \cdot C V \cdot C V\end{array}$ & 5. CV.CV.CVC'.CV \\
\hline \multicolumn{2}{|l|}{ (HEAVY Targets in bold) } \\
\hline Antepenultimate stress & Penultimate stress \\
\hline $\begin{array}{l}\text { 6. CV } \cdot \mathrm{CV}^{\prime} \cdot \mathrm{CV} \cdot \mathrm{CVC} \\
\text { 8. CV } \cdot \mathrm{CVC}^{\prime} \cdot \mathrm{CV} \cdot \mathrm{CV} \\
\text { 9. CVC.CV'.CV.CV }\end{array}$ & $\begin{array}{l}\text { 7. CV.CV.CVC'.CV } \\
\text { 10. CV.CVC.CVC'.CV }\end{array}$ \\
\hline
\end{tabular}

TABLE III. Target words. (Target syllables in bold)

\begin{tabular}{lll}
\hline Word template & \multicolumn{1}{c}{ Word } & \multicolumn{1}{c}{ Gloss } \\
\hline 1. CV.CV'.CV.CV & faba'rada & 'he got cold' \\
2. CV.CV'.CV.CV & la9a'dado & 'for his number' \\
3. CV.CV'.CV.CV & lada'baho & 'he could have killed him' \\
4. CV.CV'.CV.CV & daxa'lahu & 'he entered it' \\
5. CV.CV.CV'C.CV & fadaba'kha & 'he danced it' \\
6. CV.CV'.CV'.CVC & laba'ladak & 'for your country' \\
7. CV.CV.CV'C.CV & la?ada'bro & 'I will show him! \\
8. CV.CV'C.CV.CVC & fada'bbarak & 'he took care of you' \\
9.CVC.CV'.CV.CV & dabba'ratak & 'she took care of you' \\
10.CV.CVC.CV'C.CV & fadabba'rha & 'he took care of it' \\
\hline
\end{tabular}

of five types (types 6-10) were the same, except that they had heavy (closed) target syllables. Note that using a heavy target syllable meant that form \# 7 had a stressed target, unlike form \# 2, which had an unstressed target. The actual words used are given in Table III; target syllables had /d/ onsets and /a/ in the nucleus. Also, since we were interested in affects of prosodic structure on formant values, words did not contain emphatics or uvulars, which have been shown to affect formant values throughout a word which contains them (Zawaydeh, 1997). Most of the words were colloquial forms, although some formal register forms, such as barada (the colloquial form is barad) were included in order to obtain multi-syllabic forms which were more closely matched in segmental make-up.

The words and prosodic conditions were randomized including five repetitions. Speech was recorded with a portable Marantz cassette recorder and analyzed using SoundScope on a Mac II in the Indiana University Phonetics Lab.

Measurements included vowel durations, an estimate of the value of the first formant, and the fundamental frequency at the midpoint of each vowel. Vowel durations of the target syllables were measured from $300 \mathrm{~Hz}$ bandwidth spectrograms. They included material from the burst of the initial consonant to the cessation of high frequency energy 
indicative of stop closure following the vowel. First formant $\left(\mathrm{F}_{1}\right)$ values were extracted in the temporal center of the target syllables by means of a 13th order LPC analysis with a $20 \mathrm{~ms}$ Hamming window. Finally, fundamental frequency $\left(\mathrm{F}_{0}\right)$ measurements were calculated using an autocorrelation routine and extracted from the mid-point of each vowel in each target word. In some cases where autocorrelation $\mathrm{F}_{0}$ values were suspect, they were calculated from a waveform display.

Measurements were subject to 2- or 3-factor ANOVAs to determine the significance of differences observed between prosodic categories. One factor in each of these analyses was subject, thus giving some indication as to the homogeneity of the effects across the four subjects. The other factors were determined by specific questions to be asked of the corpus. Factors included stress, position-in-word, and - for later analyses which dealt with the effects of higher level prosodic structure - boundary strength. Syllable weight was also considered in analyzing duration and formant values, since the existence of coda consonants is likely to affect these measurements. Post-hoc $t$-tests with a Tukey compromise alpha-level correction were conducted on multi-level factors which proved significant. The tests described in the preceding paragraph treat subjects as a fixed effect and allow for inference only about the four individuals studied. These will be referred to as fixed-effects tests. To assess the likely generalizability of treatment effects to other subjects, we also subjected the data to repeated measures ANOVAs, using the same experimental factors, but treating subjects as a random effect. Most of our conclusions are confined to those effects for which significance decisions agree on both fixed-effects and repeated measures analyses. However, because of the small sample size (four subjects), the repeated measures analysis cannot be expected to have much statistical power. Factors that are deemed significant only by the fixed effects analysis (but not by the repeated measures analysis) should therefore not be dismissed out of hand in future research. We will offer some tentative interpretation in some such cases below.

\section{Results}

\subsection{Durational patterns}

Before turning to durational differences due to stress, we begin by examining durational patterns corresponding to word position. A 3-factor fixed-effects ANOVA with positionin-word (i.e., the location of the syllable within the word), syllable weight, and speaker indicated an effect of subject $(\mathrm{F}(3,540)=16.79, p<0.0001)$ and of position in word $(\mathrm{F}(3,540)=111.84, p<0.0001)$ as well as an interaction between position and whether the syllable was heavy or light $(\mathrm{F}(3,540)=7.79, \mathrm{p}<0.0001)$. Other effects were not significant. In a repeated measures analysis, the position-in-word $(\mathrm{F}(3,9)=60.04, p<0.001)$ and position by weight interactions $(\mathrm{F}(3,9)=4.89, p<0.05)$ were significant. The effects of position-in-word and syllable-weight are shown in Fig. 1. Post-hoc analyses show that the position results are due mostly to final lengthening; vowels in last syllables are almost twice as long as those in syllables in the first two positions. Two other effects are of note here. First, the interaction between weight and position is due to a greater amount of final lengthening for vowels in light syllables (hollow symbols) than those in heavy syllables. This result matches descriptions of final lengthening in English such as in Beckman and Edwards (1990), as an effect reaching in from the final edge, that is, showing less and less effects on items further from the boundary. In light syllables, the vowel is immediately adjacent to the boundary, while in the heavy syllable, a consonant intervenes. 


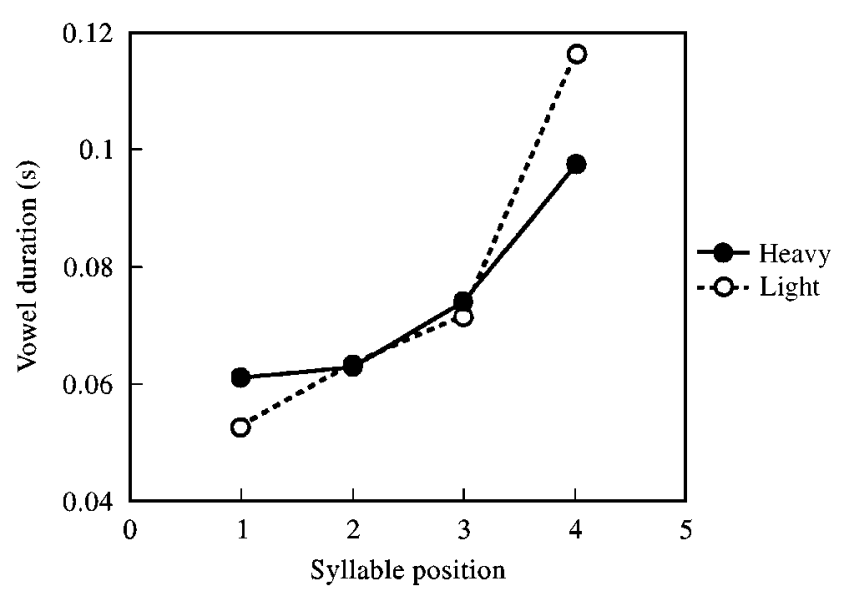

Figure 1. Mean vowel duration by position and weight.

A second significant difference is between the penultimate and antepenultimate syllable. Vowels in penultimate syllables are longer than those in antepenultimate syllables. This type of effect has not been demonstrated as a consistent effect in English. For example, Nakatani, O'Connor, and Aston (1981) found consistent positional lengthening in final syllables only. However, they also noted that earlier syllables did lengthen with two of their three subjects. It is possible to construe this difference as an extension of the final lengthening effects to a syllable previous to the final syllable. However, before pursuing this further, we must consider the fact that stress location is unevenly distributed across the second and third syllables. Thus, we must ensure this effect is not really just a difference due to the presence of stressed syllables in the penultimate position.

We turn first to vowel duration as a correlate of stress. To do this, we compared syllables in the antepenultimate position (types 3, 5, 8, and 10), since these types were where the target syllable varied in stress without changing position. Here, a 3-factor fixedeffects ANOVA (subject by weight by stress) showed that, while vowels in heavy and light syllables were not significantly different in duration $(\mathrm{F}(1,208)=0.99, p>0.05)$, vowels in stressed syllables are significantly longer than those in unstressed syllables $(\mathrm{F}(1,208)=26.71, p<0.0001)$. There was also a main effect of subject $(\mathrm{F}(3,208)=$ $42.46, p<0.0001$ ), but none of the interactions were significant. A repeated measures analysis also indicates only a significant effect of stress $(\mathrm{F}(1,3)=56.13, p<0.001)$. The stress effects are plotted in Fig. 2.

However, this stress effect does not account for the difference in vowels beween 3rd and 2nd syllables. We extracted the light syllables in $3 \mathrm{rd}$ position (which were unstressed, type 2), to compare them with unstressed light syllables in 2nd position (type 5). Also, we extracted the heavy syllables in 3rd position (which were stressed, type 7) to compare them with stressed syllables in 2nd position (type 8). A 3-factor fixed-effects ANOVA of this data indicates independent main effects of stress/weight $(\mathrm{F}(1,220)=10.61, p<0.01)$ and of position $(\mathrm{F}(1,220)=47.16, p<0.0001)$. Subject also was a significant factor $(\mathrm{F}(3,220)=31.91, p<0.0001)$, as was the interaction between subject and syllable weight $\mathrm{F}(3,220)=4.18, p<0.01)$, which seems to be due to one of the subjects (S2) exhibiting larger stress effects than the other subjects. A repeated measures analysis only indicates a significant effect of position-in-word $(\mathrm{F}(1,3)=17.70, p<0.05)$, while stress effects were not significant here $(\mathrm{F}(1,3)=2.42, p>0.10)$. Thus, there are two, separable 


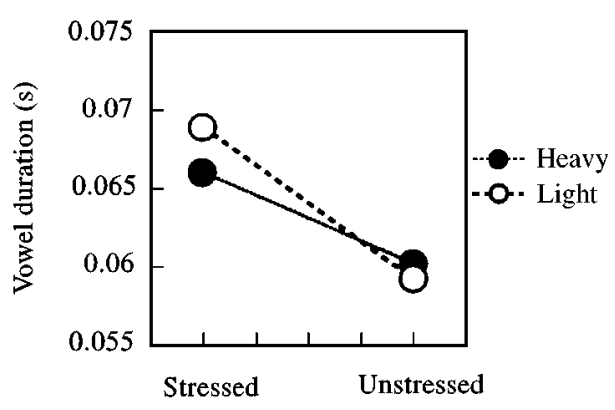

Figure 2. Mean vowel durations by stress and weight. Syllables analysed were those underlined in the following templates: Types 3 (CV.CV'.CV.CV),

5 (CV.CV.CVC'.CV), 8 (CV.CVC'.CV.CV), and 10 (CV.CVC.CV.CV). (Stress indicated in bold.)

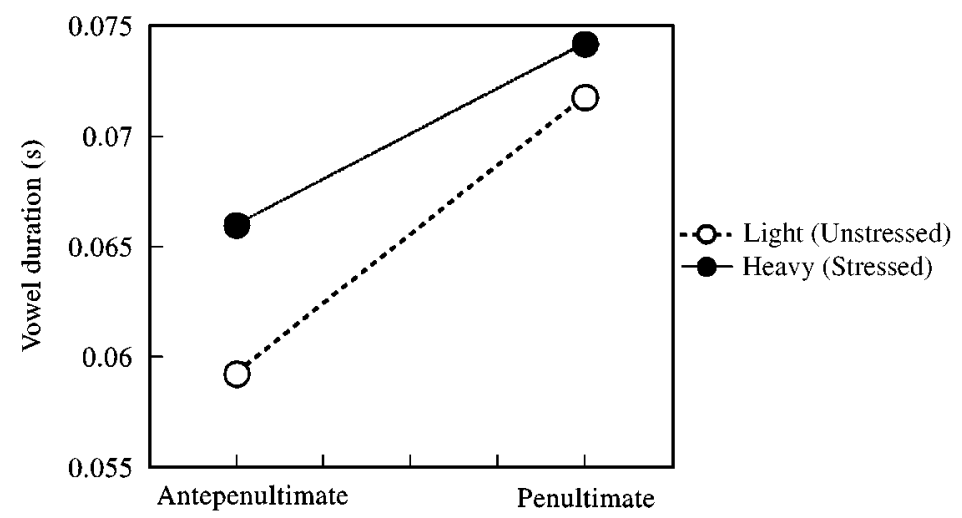

Figure 3. Mean vowel durations by position and stress. Syllables analysed were those underlined in the following templates: Types 2 (CV.CV'.CV.CV),

5 (CV.CV.CVC'.CV), 7 (CV.CV.CVC'.CV), and 8 (CV.CVC'.CV.CV.). (Stress indicated in bold.)

durational effects in these word internal syllables: stress-lengthening and preboundary lengthening. While the positional lengthening is clearly consistent across subjects, the stress lengthening is less consistent. The stress/weight and position effects are plotted in Fig. 3.

\subsection{Formant patterns}

The analysis of formant patterns casts a somewhat different light on the penultimate syllable phenomenon. First, our analyses show that stress not only increases the duration of a vowel, but also tends to increase the formant differences between vowels. A 3-way fixed-effects ANOVA (subject by stress by weight) indicates that stressed /a/ has a systematically higher $\mathrm{F}_{1}(\mathrm{~F}(1,209)=11.85, p<0.001)$. This difference, however, is not entirely consistent across subjects, as was apparent in a significant 3-way interaction between subject, stress, and syllable weight $(\mathrm{F}(3,109)=5.66, p<0.01)$. The subject factor was also significant $(\mathrm{F}(3,209)=102.83, p<0.0001)$; other effects were not. This 


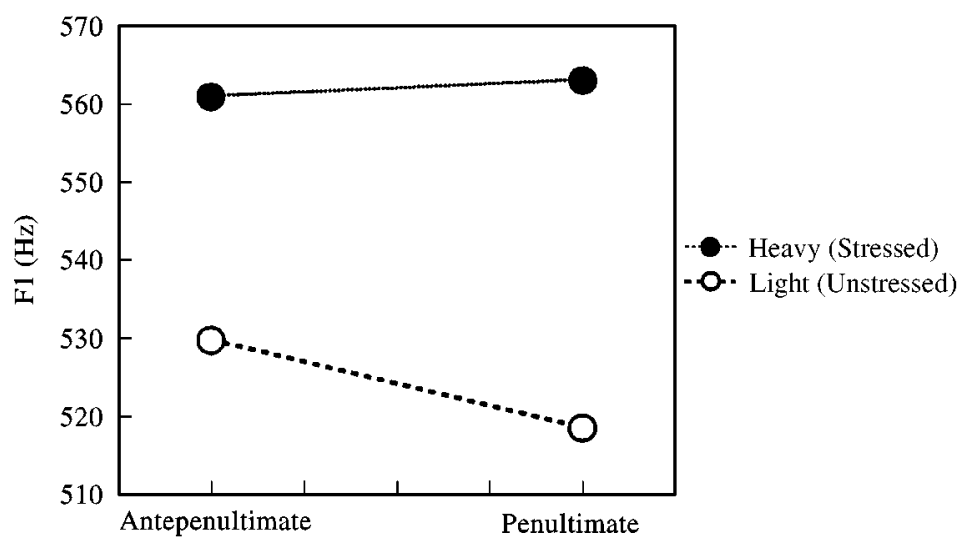

Figure 4. Mean first formant values by position and stress. Syllables analyzed are those in Fig. 3.

cross-subject inconsistency was also indicated in the results of a repeated measures ANOVA, where stress $(\mathrm{F}(1,3)=8.82, p>0.10)$ and weight $(\mathrm{F}(1,3)=5.38, p>0.10)$ were not significant.

In contrast to stress, the difference between penultimate and antepenultimate syllable position does not seem to reliably influence $F_{1}$. As in the case of duration, we extracted type 2 (unstressed/light, 3rd position), type 5 (unstressed/light, 2nd position), type 7 (stressed/heavy, 3rd position), and type 8 (stressed/heavy, 2nd position) syllables to examine the effects of position in a subset of balanced stress/weight conditions. The means of $F_{1}$ for these four syllable types are shown in Fig. 4. A three-way fixed-effects ANOVA (stress/weight by position by subject) reveals a significant difference for stress/weight $(\mathrm{F}(1,221)=27.64, p<0.0001)$. There is, however, not a significant effect for position $(\mathrm{F}(1,221)=0.041, p>0.10)$, nor for any interactions. The subject main effect was highly significant $(\mathrm{F}(3,221)=62.13, p<0.00001)$. In a repeated measures analysis, neither of the treatment factors reached significance (stress/weight, $F(1,3)=8.37$, $p>0.10$; position, $\mathrm{F}(1,3)=0.18, p>0.10)$.

If we examine the relationship, then, between the durational lengthening and $F_{1}$ value, the difference between the effect of position and the effect of stress becomes apparent. Fig. 5 illustrates the difference. The upper symbols indicate the means for the heavy syllables, the lower (hollow) symbols indicate means for the light syllables. The stress differences are shown as the difference between squares (unstressed) and circles (stressed). The effect is expressed as a diagonal vector, an increase in both duration and $F_{1}$. The effect of lengthening (circle to diamond in the heavy tokens, and square to diamond in the light tokens) only exhibits a change in duration, with no accompanying increase in $\mathrm{F}_{1}$.

These results are reminiscent of a distinction drawn by Edwards et al. (1991) between durational lengthening due to prominence increase (described by de Jong, 1995, as localized hyperarticulation), and lengthening due to the up-coming occurrence of a final edge (described by Edwards et al. as a localized decrease in tempo). Edwards et al. found these differences in a series of studies of English utterances, again underscoring the similarity of the effects found here for Arabic and what has been found for English. There remains, however, a difference between the current results and those for English, a consistent effect 


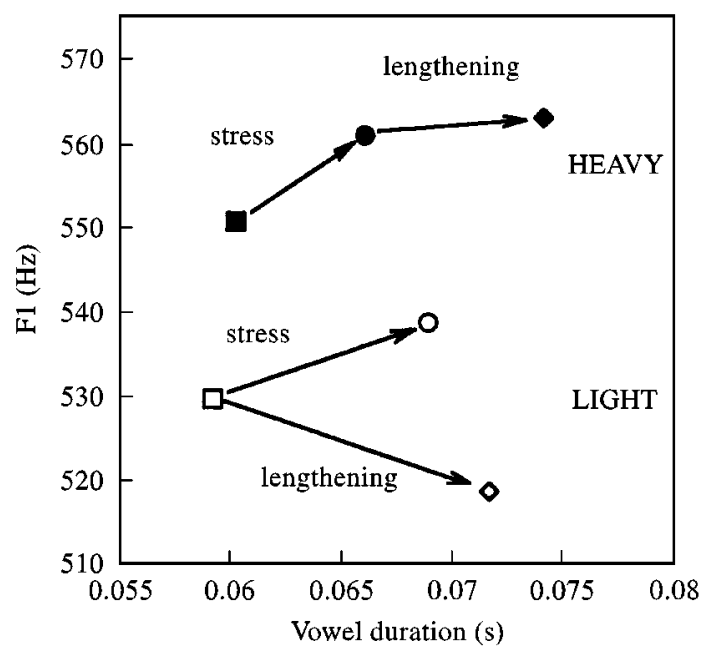

Figure 5. $F_{1}$ plotted against vowel duration for different stress and word positions. $\diamond$ Light-unstressed-3rd syllable; $\bigcirc$ Light-stressed-2nd syllable; $\square$ Light-unstressed-2nd syllable; $\bullet$ Heavy-stressed-3rd syllable; 0 Heavystressed-2nd syllable; $\mathbf{D}$ Heavy-unstressed-2nd syllable.

of pre-boundary lengthening as far as one syllable away from a word edge. This difference will be discussed below.

\subsection{Fundamental frequency patterns}

We turn to an examination of the $F_{0}$ patterns. Preliminary analyses of the raw data indicate that the $\mathrm{F}_{0}$ patterns are extremely complicated, exhibiting a plethora of subject and prosodic condition differences. This is as one would expect if Arabic intonation patterns are, like those in English, governed by speaker's expression of poorly controlled discourse considerations. Before addressing the connection between stress and $\mathrm{F}_{0}$ statistically, we begin by describing the $F_{0}$ contours for each prosodic condition for each subject.

Fig. 6 shows $\mathrm{F}_{0}$ contours for words spoken as statements in isolation for two stress locations. (Filled symbols indicate tokens with penultimate stress; hollow symbols indicate tokens with antepenultimate stress.) Each subject has a rise to a peak over the stressed syllable and terminal fall, except for S3, who exhibits a fall after the stressed syllable and a terminal rise when the stress falls on the antepenultimate (2nd) syllable. Similar patterns appear for words embedded in longer phrases, though with some complications. Fig. 7 shows $F_{0}$ contours for the non-phrase-final and phrase-final statement conditions for each subject. The patterns for S1 are essentially the same as in isolation. This is the pattern expected with the association of a high pitch accent to the stressed syllable and a terminal declarative low tone. S2 and S4 (to the right) do not have a terminal low in cases where the target word is non-final (circles). Instead, these subjects show a high plateau after the stressed syllable, possibly indicative of something like a high phrase accent. Additional complications include S4 beginning the final high plateau one syllable after the stressed syllable in non-final cases (circles), and S2's final 

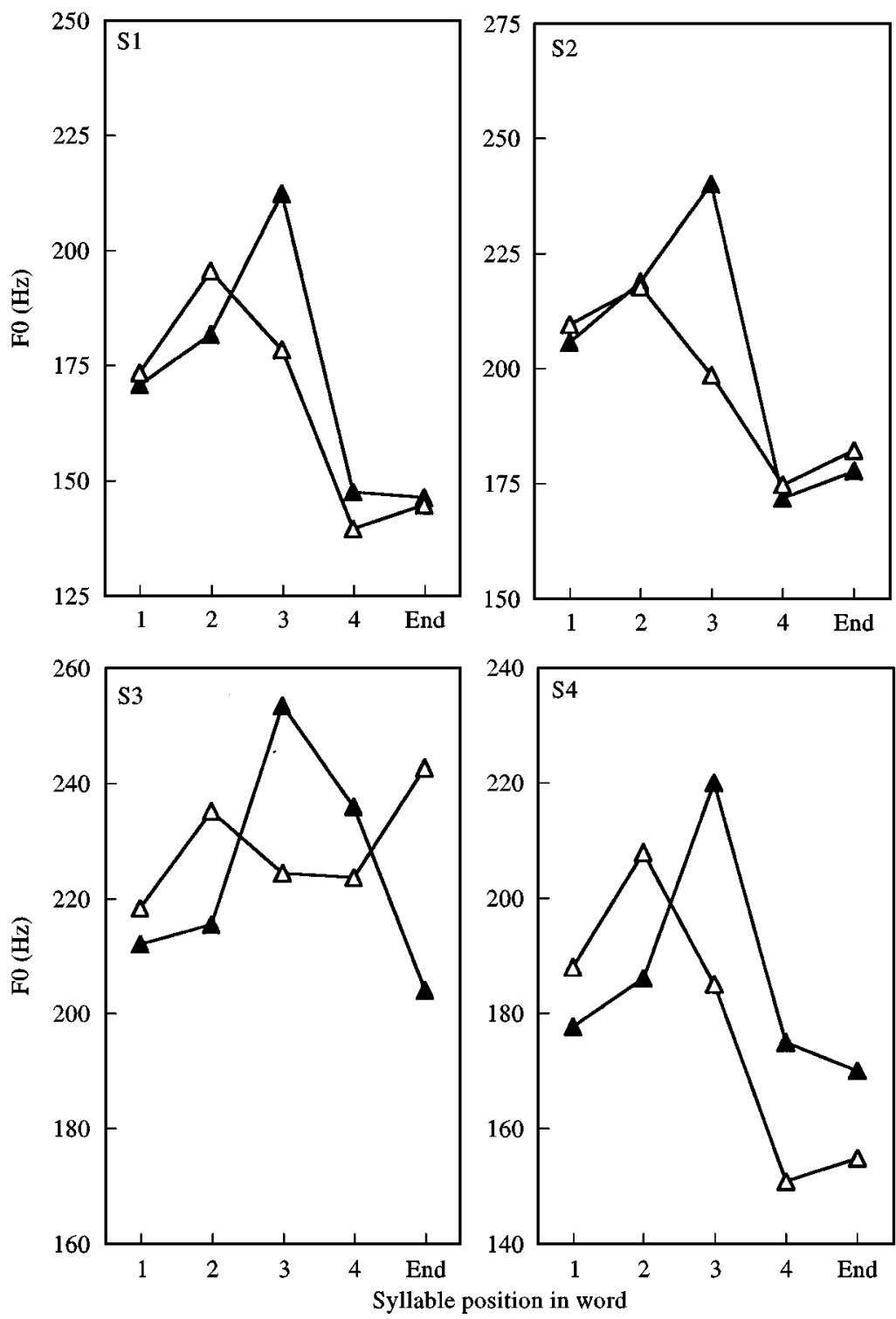

Filled: Stress on Syllable 3

Hollow: Stress on Syllable 2

Figure 6. $\mathrm{F}_{0}$ plotted by position for isolation conditions.

words having peaks one syllable before the stressed syllable regardless of stress location (triangles). S3's data is complicated. Words in non-phrase-final position seem to exhibit no final phrase marker at all and possibly are also missing a pitch accent associated with the stressed syllable (filled circles). In addition, the final tone pattern depends on the location of the stress for isolation and final conditions. Words with antepenultimate stress have high peak on the stressed syllable and low-high phrasal pattern at the final edge; words with penultimate stress also have a high peak on the stressed syllable followed by a terminal low. 

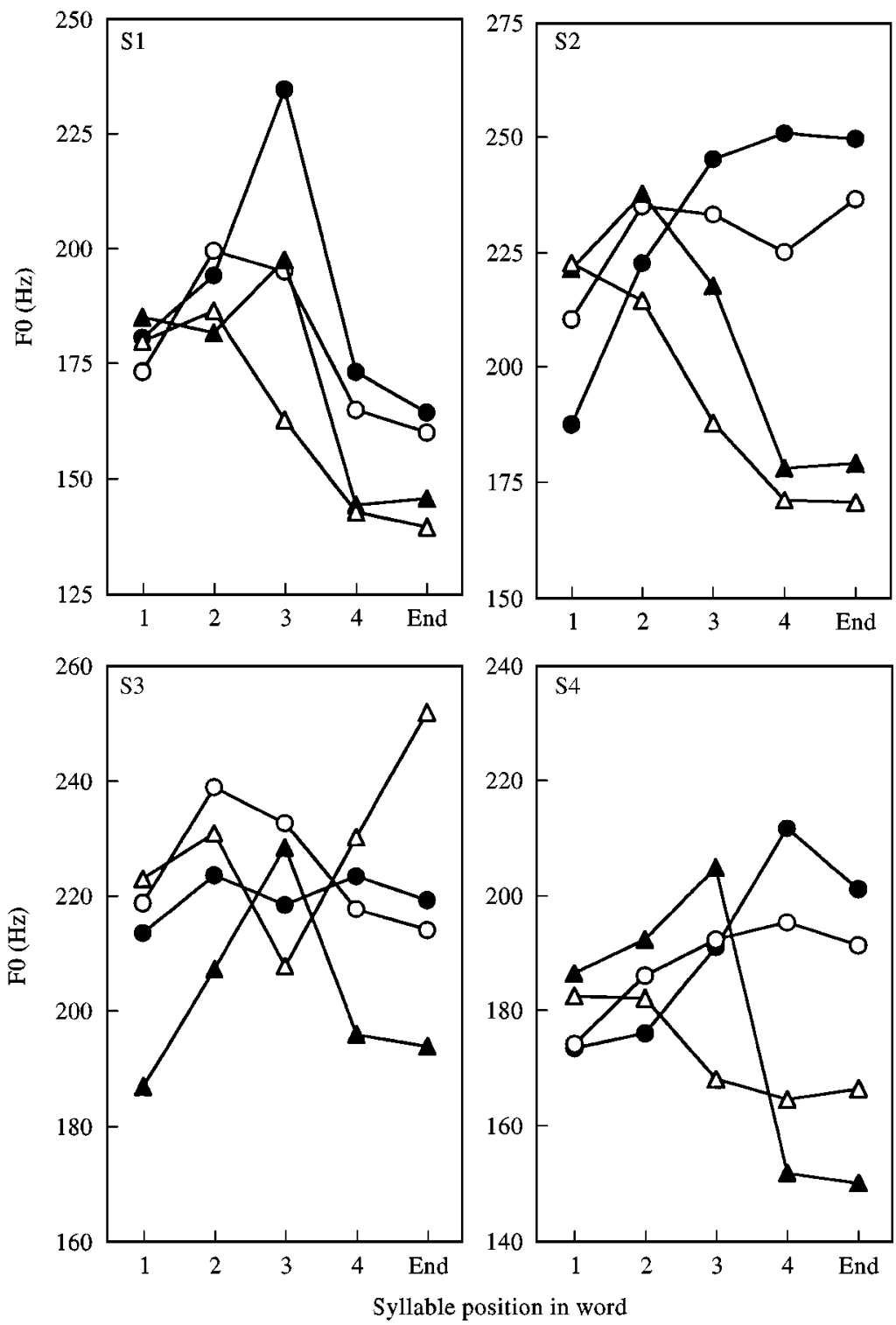

$\Delta$ phrase-final
O non-phrase-final

Filled: Stress on Syllable 3

Hollow: Stress on Syllable 2

Figure 7. $\mathrm{F}_{0}$ plotted by position for statement (non-isolation) conditions.

Fig. 8 shows $F_{0}$ contours for morphologically covert questions. Here, the patterns are somewhat more difficult to interpret. S1 exhibits a terminal rise which seems indicative of a high boundary tone. The curious aspect of S1's utterances is that the rise does not begin at the stressed syllable, as would be expected if Arabic speakers used the combination of low pitch accents with high boundary tones to mark questions. S2, S3, and S4 seem to utilize a low-high phrase final complex on final words (triangles). S2 and S3 couple this with a high accent on the stressed syllable, while S4 shows no evidence for accenting. 

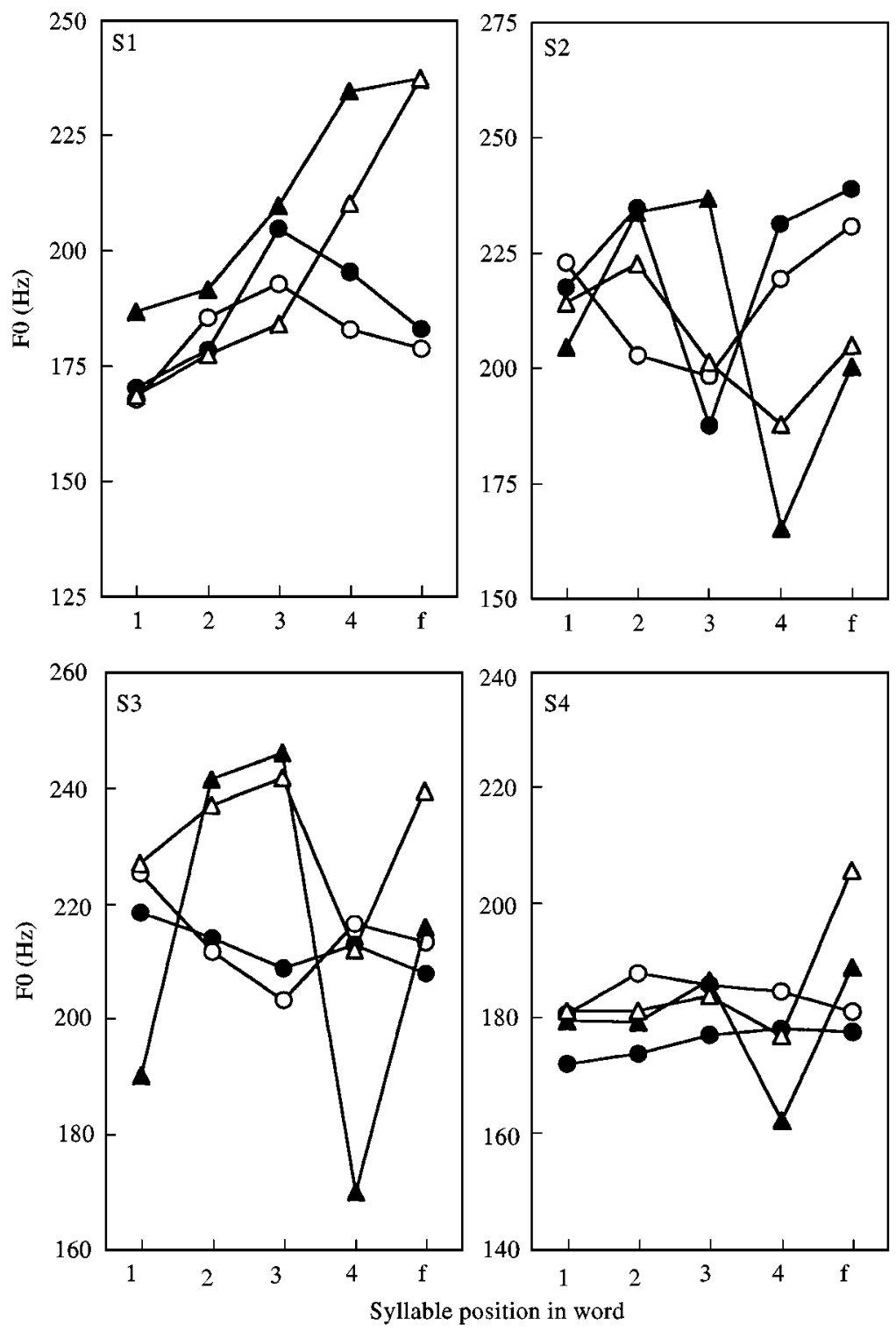
$\Delta$ phrase-final
O non-phrase-final
Filled: Stress on Syllable 3
Hollow: Stress on Syllable 2

Figure 8. $F_{0}$ plotted by position for question conditions.

Non-phrase-final words for S3 show some evidence for low tone minima: however, it's not clear whether there are differences according to stress condition (circles). S2 exhibits a sharp fall onto the stressed syllable, probably indicative of a low-toned accent.

These patterns are summarized in Table IV, coded using Pierrehumbert's (1980) tonal transcriptions of likely English analogs. Here, likely alternative analyses are included in parentheses, while question marks indicate that there are some problems with the alignment of the accent with the stressed syllable. The most consistent aspects of the 
TABLE IV. Analyses of $F_{0}$ patterns per speaker

\begin{tabular}{|c|c|c|c|c|}
\hline & \multicolumn{2}{|c|}{$\begin{array}{l}\text { Non-phrase-final } \\
\text { (Circles in figures) }\end{array}$} & \multicolumn{2}{|c|}{$\begin{array}{c}\text { Phrase-final } \\
\text { (Triangles in figures) }\end{array}$} \\
\hline & Pitch accent & Phrase marker & Pitch accent & Phrase marker \\
\hline \multicolumn{5}{|l|}{ Statements } \\
\hline $\mathrm{S} 1$ & $\mathrm{H}^{*}$ & L: or LL\% & $\mathrm{H}^{*}$ & LL\% \\
\hline S2 & $\mathrm{H}^{*}$ & H: (or HL\%) & $\mathrm{H}^{*}$ ? & LL \% \\
\hline S3 & $\mathrm{H}^{*}$ or none & L: (or none) & $\mathrm{H}^{*}$ & LL\% or $\mathrm{HH} \%$ \\
\hline S4 & $\mathrm{H}^{*}$ ? (or none) & $\mathrm{H}$ : (or none) & $\mathrm{H}^{*}$ & LL $\%$ \\
\hline \multicolumn{5}{|l|}{ Questions } \\
\hline S1 & $\mathrm{H}^{*}$ (or none) & none & L*? (or none) & HH $\%$ \\
\hline $\mathrm{S} 2$ & $\mathrm{H}+\mathrm{L}^{*}$ & H: (or HL\%) & $\mathrm{H}^{*}$ & LH\% \\
\hline S3 & L*? (or none) & L: (or none) & $\mathrm{H}^{*}$ ? & LH \% \\
\hline S4 & none (or $\mathrm{L}^{*}$ ) & L: (or none) & none (or $\mathrm{L}^{*}$ ) & LH\% \\
\hline
\end{tabular}

* indicates a tone aligned to the stressed syllable for a pitch accent : indicates an intermediate phrase tone

$\%$ indicates an intonation phrase-final boundary tone

? indicates a problem with the alignment of the pitch accent

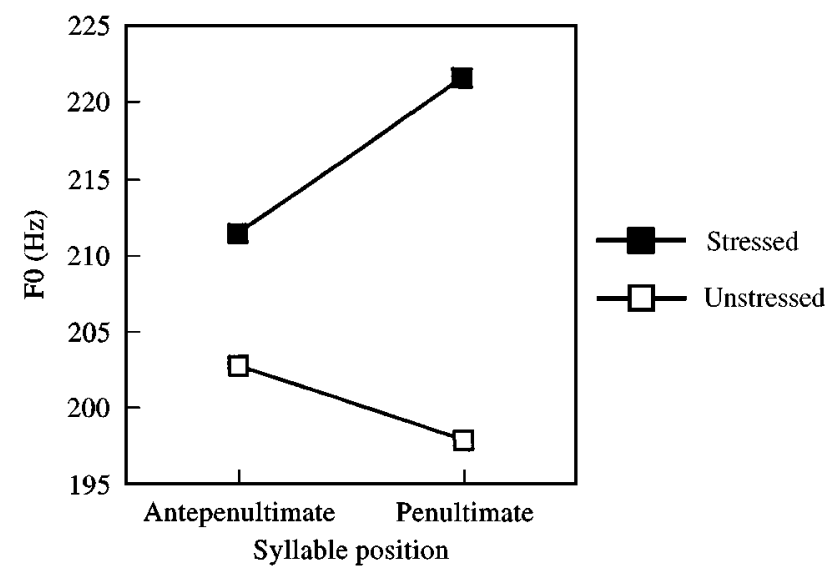

Figure 9. $\mathrm{F}_{0}$ contours across penultimate and antepenultimate syllables for different stress locations. Averages are across statement conditions only.

intonational pattern are the phrase final markers - most speakers using LL\% contours for statements and $\mathrm{LH} \%$ for question marking. Also, high pitch accents commonly occur in statements.

With this general background, the question of $F_{0}$ differences associated with stress can be addressed. If we examine words in statement conditions only (where there seems to be a strong preponderance of high accents), we find stress associated with an increase in $\mathrm{F}_{0}$, as illustrated in Fig. 9, which plots means for stressed and unstressed syllables. This observation was supported by a fixed-effects ANOVA of $F_{0}$ values in stressable syllables (penultimate and antepenultimate) in statement conditions using stress, syllable position, 
and subject as factors. This analysis shows a strong effect of stress location $(\mathrm{F}(1,686)=$ $60.39, p<0.0001$ ), such that $\mathrm{F}_{0}$ is higher in (high-tone accented) stressed syllables, and an interaction between stress and syllable position $(\mathrm{F}(1,686)=16.66, p<0.0001)$, such that $F_{0}$ differences between stressed and unstressed syllables are greater in penultimate than in antepenultimate syllables. The subject factor was also significant $(\mathrm{F}(3,686)=$ $83.13, p<0.0001)$ as was the three-way interaction $(\mathrm{F}(3,686)=4.65, p<0.01)$. A repeated measures analysis indicates that the stress effect is significant $(F(1,3)=$ $40.14, p<0.01)$, while the position by stress interaction does not generalize well across subjects $(\mathrm{F}(1,3)=3.58, p<0.10)$.

\subsection{Relationships between higher-level prosody and word-level effects}

One final aspect of the present data to be examined is the possible linkage of the word-level durational effects to higher level prosodic structure. To do this, we grouped words produced by each subject according to an estimate of typical intonational pattern used in each prosodic condition.

First, we examine the final lengthening effect illustrated in Fig. 1. Vowels in word-final syllables were separated by the nature of the following boundary. Three levels were indicated: sentence-final, non-sentence-final with a clear intonational movement between the stressed syllable and the end of the word, and non-sentence-final with a typically flat $\mathrm{F}_{0}$ pattern between the stressed syllable and the end of the word. This latter distinction is based on the idea that $\mathrm{F}_{0}$ contours after the stressed syllable are indicative of phrase accents or boundary tones which mark a particular phrase boundary, as is claimed of English, for example, by Pierrehumbert and Beckman (1988). A 2-way fixed-effects ANOVA with subject and boundary type as factors indicated a significant effect of boundary type $(\mathrm{F}(2,106)=8.66, p<0.001)$, but no significant subject effects $(\mathrm{F}(3,106)=$ $2.17, p>0.05)$ or interaction $(\mathrm{F}(6,106)=1.66, \mathrm{p}>0.05)$. Fig. 10 plots vowel durations before the different boundaries. Post-hoc tests indicate that the sentence final condition differed from the other two, while the other two (which were differentiated by intonational classification) did not differ significantly, though there was a trend in the direction of tonally marked boundaries creating longer final vowels. Note, however, that a repeated measures analysis shows a nonsignificant effect of boundary type $(F(2,6)=$ $5.23, p>0.10)$.

Second, the penultimate lengthening effect was also examined with respect to the different boundary types. To do this, the subset of the corpus which was balanced for stress and included penultimate and antepenultimate syllables was extracted (types 2,5,7,8, as described above in Sections 3.1 and 3.2). These durations were analyzed separately for words preceding the three types of boundaries. Three-way fixed-effect ANOVAs (such as the one reported in Section 3.1) showed that, as the prosodic size of the break following the word gets larger, the size of the effect of stress gets smaller. Data for words which showed no clear evidence of having an intonational boundary marker are plotted in the left panel of Fig. 11. Here, there are significant effects of both stress $(\mathrm{F}(1,32)=10.55, p<0.01)$ and position-in-word $(\mathrm{F}(1,32)=20.53, p<0.0001)$. Subject was also a significant factor in this analysis, but none of the interactions were. A repeated measures analysis also indicates significant effects of stress $(\mathrm{F}(1,3)=27.06, p<0.05)$, and position $(\mathrm{F}(1,3)=81.62, p<0.01)$. However, a fixed-effect analysis of non-final words in prosodic conditions with clear intonational phrase markers did not exhibit a significant effect of stress $(\mathrm{F}(1,32)=2.54, p>0.05)$, while still showing a significant amount of 


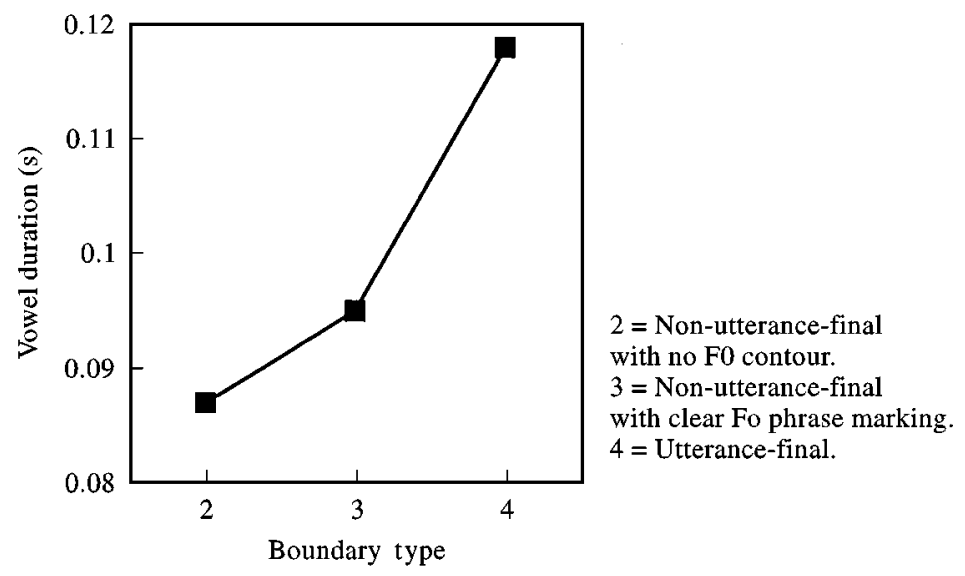

Figure 10. Vowel durations for final syllables before boundaries of different types.

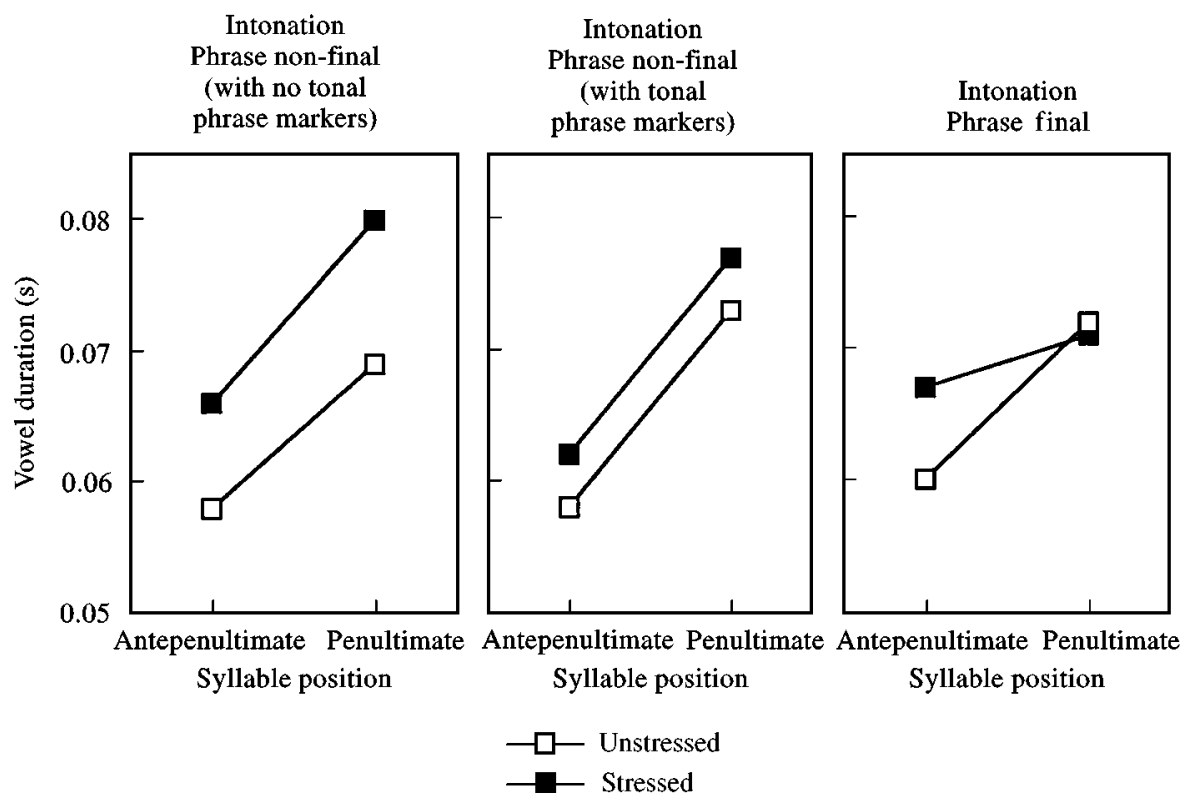

Figure 11. Vowel durations for word-medial syllables before boundaries of different types. Syllables analysed are those in Fig. 3.

lengthening in the penultimate syllable $(\mathrm{F}(1,32)=32.84, p<0.001)$. Subject was also significant here, but none of the interactions were significant $(p>0.10)$. A repeated measures analysis also indicates a significant effect of position $(\mathrm{F}(1,3)=62.28, p<0.01)$, but not of stress $(\mathrm{F}(1,3)=0.59, p>0.10)$. This data is plotted in the middle panel of Fig. 11.

Finally, sentence final tokens were also subjected to parallel analyses. Results are illustrated in the right panel of Fig. 11. Here, in a fixed-effects analysis the position-inword effect is significant $(\mathrm{F}(1,124)=15.48, p<0.0001)$, as is the subject factor, while the 
stress factor is not significant $(\mathrm{F}(1,124)=3.46, p>0.05)$. None of the interactions are significant, except for a significant three-way interaction $(\mathrm{F}(1,124)=6.47, p<0.0001)$. Further investigation into this three-way effect (by means of separate 2-way ANOVAs for each speaker) indicate that $\mathrm{S} 2$ exhibited a large stress effect with no effect of position, while S3 exhibited a large position effect without an effect of stress. The other two subjects exhibited the interaction effect evident in the overall means plotted in Fig. 11, whereby stress lengthening did not occur when syllables were penultimate. A repeated measurements analysis indicates a significant effect of position $(\mathrm{F}(1,3)=10.60, p<0.05)$, but not of stress $(\mathrm{F}(1,3)=0.99, p>0.10)$ nor of an interaction $(\mathrm{F}(1,3)=0.51), p>0.10)$. Thus, in phrase final position, stress effects on duration are for some subjects not separable from position-in-word effects.

\section{Summary and discussion}

To summarize, the current study found many word-level prosodic effects which are very similar to those found in studies of English. It found extensive word-final lengthening effects, on the order of $60 \%$ for word (and phrase) final, to $100 \%$ for utterance final syllables. These effects are considerably smaller than those found for stressed, phrasefinal syllables in English by Beckman and Edwards (1990), but larger than what they found for phrase-internal word-final effects. Comparison with the results of Nakatani et al. (1981) permits the same conclusion; the durational effects of the juncture levels examined here are between those for word and phrase in English.

The current study also revealed a very consistent but small increase in vowel durations in penultimate positions. This result is similar in quality to that found for English as well. Beckman and Edwards (1990) show large differences between phrase final and nonphrase final stressed penultimate syllables (in the word, poppa). The differences for English are much larger than those found here for Arabic; however, they also involve a stressed syllable with a following reduced syllable, while all of the syllables here contain full vowels. Nakatani et al. (1981) show small increases in antepenultimate syllable duration like those found here; however, their effects appeared for two of their four subjects, and it is not clear how robust the differences were.

Consistent with the findings of Summers (1987) and Edwards, Beckman and Fletcher (1991), our Arabic study exhibited stress lengthening, as well as a difference between phrase and stress lengthening on $F_{1}$. Stress lengthening is occasionally associated with higher $F_{1}$, while penultimate lengthening never is. As with the phrasal duration effects, the magnitude of the effects here is considerably smaller than that found of English by Nakatani et al. (1981) and others, as are the effects on $F_{1}$. Summers (1987), for example, found between a 50 and $100 \mathrm{~Hz}$ increase in $\mathrm{F}_{1}$ of low vowels with stress, while the difference found here for Arabic runs between 10 and $40 \mathrm{~Hz}$. Thus, while the word-final lengthening effects are larger in this Arabic study, the stress effects, both on duration and $\mathrm{F}_{1}$, are smaller.

One additional observation should be made concerning the difference between preboundary lengthening and stress. This study has found evidence that these two effects are different, as has been found in detailed studies of English such as Edwards et al. (1991). However, it is also apparent that the two effects are showing a tendency to interact, in that the penultimate lengthening seems to be behaving in some ways like stress. First, penultimate lengthening is more consistent in the current Arabic study than it is in other 
studies of English. Second, in phrase final position, where the pre-boundary lengthening is more pronounced, one of the current subjects does not show any stress lengthening effects, but rather a penultimate lengthening. Two other subjects exhibit inconsistent stress lengthening. Third, several of the speakers show a tendency towards a greater pitch range for accents on penultimate syllables. This shows up particularly in the current analysis in an increase in average $\mathrm{F}_{0}$ differences between stressed and unstressed syllables in penultimate position. These three sets of facts together suggest that while stress effects and accent location do indicate the variable stress location described in phonological analyses, there is also a competing prominence with fixed location on the penultimate syllable.

Analyses of $F_{0}$ patterns suggest that the intonational system utilizes optional pitch marks on stressed syllables and register and contour differences after the stressed syllable. This intonational structure is also similar to that of English. From a single study, it is difficult to draw conclusions about the inventory of pitch marks or their function; however, it does seem that the Arabic system shows both similarities and differences with that of English with regard to tonal usage. Similar are the typical appearance of high pitch accents with declarative readings and an increased incidence of low-starred pitch accents in morphologically covert questions. One clear difference in usage, however, is in the common appearance of low-high contours at the end of Arabic questions, as opposed to the high-rising contour typically found in English.

In sum, the expression of Arabic word-level prosody is remarkably like that of English, both in the expression of stress and linkage of pitch accents to stressed syllables and in the occurrence of pre-boundary lengthening. This similarity in the quality of these effects is particularly remarkable since the languages are not closely historically related. A point to be addressed, then, is why do such disparate languages exhibit such similarity? It is, of course, possible that the similarity of the two language's word-level prosody is simply an accident. However, this seems unlikely. For instance, a very similar cohort of physical differences have also been found associated with stress in Gaelic (Bosch and de Jong, 1997), and we suspect that more cases will continue to appear with more quantitative work on stress in different languages. Thus, the answer to this question likely has more to do with the physical and cognitive manifestation of language than to linguistic convention.

Stress accent and junctural lengthening would appear to be tools, provided by physics, physiology, and cognition, which can be implemented as an aspect of prosodic organization by a linguistic community, in much the same way that tongue-tip closure can be used by a community for expressing contrasts and demarcating syllables. This is not, however, to say that prosodic systems are stereotypical. The Arabic speakers exhibit different amounts of both stress lengthening and pre-boundary lengthening than are typical in studies of English. Thus, the degree to which these prosodic effects will be manifested in a particular system is part of the linguistic convention which needs to be specified for a particular language. Whether such differences are associated with other aspects of the linguistic system, such as the systematic usage of quantity contrasts or differences in the number and size of prosodic domains in the two systems, is a question to be addressed by further research.

Data gathering was supported by an Indiana University Grant-in-Aid and Fred Householder Memorial Grant to Bushra Zawaydeh. We thank the speakers who so graciously offered their time for this study. Portions of this data were presented at the 1998 Texas Linguistic Forum. We also 
acknowledge the useful comments by Fares Mitleb, Terry Nearey, Bruce Derwing, and two anonymous reviewers on an earlier draft of this paper.

\section{References}

Abdo, D. A. (1969) Stress and Arabic Phonology. Ph.D. dissertation, University of Illinois at UrbanaChampaign.

Al-Ani, S. (1992) Stress variation of the construct phrase in Arabic: a spectrographic analysis. Anthropological Linguistics, 34, 258-276.

Al-Mozaini, H. A. (1981) Vowel Alternations in a Bedouin Hijazi Arabic Dialect: Abstractness and Stress. Ph.D. dissertation, University of Texas at Austin.

Al-Mozaini, H. A., Bley-Uroman R. \& McCarthy, J. (1985) Stress shift and material structure. Linguistic Inquiry, 16, 135-144.

Angoujard, J.-P. (1990) Metrical Structure of Arabic. Dordrecht: Foris Publications.

Beckman, M. E. \& Edwards, J. R. (1990) Lengthenings and shortenings and the nature of prosodic constituency. In Papers in Laboratory Phonology I: Between the Grammar and Physics of Speech. (J. Kingston and M. E. Beckman, eds.), pp. 152-178. Cambridge: Cambridge University Press.

Beckman, M. E. \& Pierrehumbert, J. B. (1986) Intonational structure in Japanese and English. Phonology Yearbook 3, 255-310.

Bolinger, D. (1958) A theory of pitch accent in English. Word, 7, 199-210.

Bosch, A. R. K. \& K. de Jong (1997) The prosody of Barra Gaelic epenthetic vowels. Studies in the Linguistic Sciences, 27, 1-16.

Brame, M. (1974) The cycle in phonology: Stress-Palestian, Maltese and Spanish. Linguistic Inquiry, 5, 39-60.

Broselow, E. (1976) The Phonology of Egyptian Arabic. Ph.D. dissertation, University of Massachusetts.

Cummins, F. (1997) Rhythmic Coordination in English Speech: an Experimental Study. Ph.D. dissertation, Indiana University. Distributed as Technical Report \# 198 of the Indiana University Cognitive Science Program, Bloomington, Ind.

de Jong, K. (1995) The supraglottal articulation of prominence in English: Linguistic stress as localized hyperarticulation. Journal of Acoustical Society of America, 97(1), 491-504.

Edwards, J. R., Beckman, M. E. \& Fletcher, J. (1991) The articulatory kinematics of final lengthening. Journal of the Acoustical Society of America, 89, 369-382.

Farwaneh, S. (1995) Directionality Effects in Arabic Dialect Syllable Structure. Ph.D. dissertation, University of Utah.

Fry, D. B. (1955) Duration and intensity as physical correlates of linguistic stress. Journal of the Acoustical Society of America, 27, 765-768.

Fry, D. B. (1958) Experiments in the perception of stress. Language and Speech, 1, 126-152.

Fry, D. B. (1965) The dependence of stress judgements on vowel formant structure. In Proceedings of the 5th International Congress of Phonetic Sciences, Munster, pp 306-311. Basel and New York: S. Karger.

Glover, B. C. (1988) The Morphophonology of Muscat Arabic. Ph.D. dissertation, University of California, Los Angeles.

Haliel, M. (1984) The rhythmic unit in Modern Literary Arabic. Al-Arabiyya, 17, 5-24.

Hamid, A. H. (1984) A Descriptive Analysis of Sudanese Colloquial Arabic Phonology. Ph.D. dissertation, University of Illinois at Urbana-Champaign.

Hayes, B. (1995) Metrical Stress Theory: Principles and Case Studies. Chicago: University of Chicago Press..

Irshied, O. (1984) The Phonology of Arabic: Bani Hasan - a Bedouin Jordanian Dialect. Ph.D. dissertation, University of Illinois at Urbana-Champaign.

Kager, R. (to appear) Surface opacity of metrical structure in optimality theory. In The Derivational Residue in Phonology (B. Hermans and M. van Oostedorp, eds.).

Kaye, A. S. (1997) Arabic phonology. In Phonologies of Asia and Africa, Vol. 1. (A. S. Kaye, ed.), pp. 187-204. Winona Lake: Eisenbrauns.

Kenstowicz, M. (1997) Base identity and uniform exponense: Alternatives to cyclicity. In Current Trends in Phonology: Models and Methods (J. Durand and B. Laks, eds.). Stanford: University of Stanford Publications.

Kenstowicz, M. (1983) Parametric variation and accent: the Arabic dialects. Chicago Linguistic Society, 19, $205-213$.

Kenstowicz, M. (1986) Notes on syllable structure in three Arabic dialects. Revue Quebecoise de Linguistique, 16, $101-128$.

Kenstowicz, M. \& K. Abu-Karim. (1980) Cyclic stress in Levantine Arabic. Studies in the Linguistic Sciences, 10(2), 55-76.

Lindblom, B. E. F. (1990) Explaining phonetic variation: a sketch of the H\&H theory. In Speech Production and Speech Modeling (H. J. Hardcastle \& A. Marchal, eds.), pp. 403-439. NATO ASI Seriess D: Behaviour and Social Sciences, Vol. 55. Dordrecht: Kluwer A.P. 
Majdi, B. (1988) Iraqi Arabic Morphophonemics. Ph.D. dissertation., Univ. of Connecticut..

McCarthy, J. (1979) Formal Problems in Semitic Phonology and Morphology. Ph.D. dissertation, MIT.

Distributed by Indiana University Linguistics Club, Bloomington, Ind..

McCarthy, J. (1980) A note on the accentuation of Damascene Arabic. Studies in the Linguistic Sciences, 10(2), 77-98..

Miller, M. (1984) On the perception of rhythum. Journal of Phonetics, 12, 75-83..

Nakatani, L. H., O’Connor, K. D. \& Aston C. H. (1981) Prosodic aspects of American English speech rhythm. Phonetica, 38, 84-106.

Odden, D. (1989) Aspects of Iraqi Arabic verbal phonology. Studies in the Linguistic Sciences, 8(1), 137-152.

Pierrehumbert, J. B. (1980) The Phonology and Phonetics of English Intonation. Ph.D. dissertation, M.I.T. (available through the Indiana University Linguistics Club, Bloomington, IN).

Pierrehumbert, J. \& M. Beckman. (1988) Japanese Tone Structure. Cambridge, Mass.: MIT Press..

Pierrehumbert, J. B. \& J. Hirschberg (1990) The meaning of intonational contours in the interpretation of discourse. In Intentions in Communication (P. R. Cohen, J. Morgan \& M. E. Pollock, eds.), pp. 271-311. Cambridge MA: MIT Press.

Summers, W. V. (1987) Effects of stress and final-consonant voicing on vowel production: Articulatory and acoustic analyses. Journal of the Acoustical Society of America, 82, 847-863.

Tajima, K. (1998) Speech Rhythm in English and Japanese: Experiments in Speech Cycling. Indiana University Ph.D. Thesis, Bloomington, Ind.

van de Vijver, R. (1996) Variations on an Arabic theme. In Stress Patterns of the World (R. Goedemans, H. van der Hulst \& E. Visch, eds.). The Hague: The Holland Institute of Generative Linguistics.

Zawaydeh, B. A. (1997) An acoustic analysis of uvularization spread - Ammani Jordanian Arabic. Studies in the Linguistic Sciences, 27, 185-200. 